\title{
SÍNTESE HIDROTERMAL DE SODALITA BÁSICA A PARTIR DE UM REJEITO DE CAULIM TERMICAMENTE ATIVADO
}

\author{
Simone Patrícia Aranha da Paz*, Rômulo Simões Angélica e Roberto de Freitas Neves \\ Instituto de Geociências, Universidade Federal do Pará, Rua Augusto Corrêa, s/n, 66075-110 Belém - PA, Brasil
}

Recebido em 8/3/09; aceito em 1/9/09; publicado na web em 23/2/10

\begin{abstract}
HYDROTHERMAL SYNTHESIS OF BASIC SODALITE FROM A THERMICALLY ACTIVATED KAOLIN WASTE. Basic sodalite was successfully synthesized by hydrothermal method using kaolin waste as source of Aluminum and Silicon. This waste is mainly composed by kaolinite and is produced in large amount by kaolin processing industries for paper coating from the Amazon region. Initially, the waste has been calcined at $700{ }^{\circ} \mathrm{C}$ for $2 \mathrm{~h}$ and then reacted with the following solutions: $\mathrm{Na}_{2} \mathrm{CO}_{3}$ and mixture of $\mathrm{Na}_{2} \mathrm{CO}_{3}+\mathrm{NaOH}$ to 150 ${ }^{\circ} \mathrm{C}$ with autogenous pressure for $24 \mathrm{~h}$. The raw materials and transformed materials were characterized by XRD, FTIR and SEM. In both studied media, well-crystallized, basic sodalite was the only phase synthesized, while in the literature usually a mixture of zeolites is obtained.
\end{abstract}

Keywords: synthesis; basic sodalite; kaolin waste.

\section{INTRODUÇÃO}

A região amazônica dispõe de grandes e valiosos depósitos de caulim que, por sua natureza geológica, são adequados ao seu uso mais nobre, a cobertura de papel. Só no Estado do Pará estão localizadas três grandes indústrias de beneficiamento de caulim do País, que geram de rejeito, somente nas etapas de separação granulométrica e branqueamento, mais de 1 milhão de toneladas por ano e, em função deste elevado volume, faz-se necessária a construção de onerosas lagoas de sedimentação para sua deposição. ${ }^{1-3} \mathrm{O}$ rejeito depositado nas lagoas não apresenta consistência adequada que permita o recobrimento convencional para a recuperação da área, o que o torna um problema ambiental. No entanto, a utilização desse rejeito como matéria-prima na síntese de zeólitas tem-se mostrado bastante viável, ${ }^{4,5}$ isso porque tal material é composto essencialmente por caulinita, argilomineral mais empregado como fonte de $\mathrm{Si}$ e $\mathrm{Al}$ em síntese de zeólita e de material com estrutura relacionada. ${ }^{6-9}$

A caulinita é o principal constituinte do caulim, quimicamente é um silicato de alumínio hidratado, que normalmente se encontra associada a outros minerais sob a forma de impurezas, de modo geral, quartzo, mica, feldspato, óxidos de ferro e titânio. É formada pelo empilhamento regular de camadas $1: 1$, isto é, cada camada é constituída de uma folha de tetraedros $\mathrm{SiO}_{4}$ e uma folha de octaedros de $\mathrm{Al}_{2}(\mathrm{OH})_{6}$ ligadas entre si por oxigênios comuns, dando uma estrutura fortemente polar. As ligações entre as camadas são feitas por ligações de hidrogênio, $\mathrm{OH}-\mathrm{O}$, uma vez que existe um plano de íons hidroxila numa das faces da camada e um plano de íons oxigênio na outra camada adjacente. A energia de ligação costuma variar para cada espécie, mas no geral é preciso temperaturas entre 500 e 700 ${ }^{\circ} \mathrm{C}$ para que todas as $\mathrm{OH}^{-}$sejam eliminadas. A fórmula estrutural da cela unitária da caulinita é $\mathrm{Al}_{2} \mathrm{Si}_{4} \mathrm{O}_{10}(\mathrm{OH})_{8}$ e a composição percentual: $\mathrm{SiO}_{2}-46,54 \%, \mathrm{Al}_{2} \mathrm{O}_{3}-39,50 \%$ e $\mathrm{H}_{2} \mathrm{O}-13,96 \% .^{10-13}$

As zeólitas são aluminossilicatos hidratados com uma estrutura cristalina de geometria precisa e nanoporos de tamanho uniforme, formando canais de dimensões moleculares, com propriedades especiais para serem usadas como peneira molecular, adsorvente e trocador iônico seletivo. ${ }^{6,14,15}$ Vinham sendo, historicamente, consideradas tectossilicatos, por serem formados de uma rede tridimensional de tetraedros $\mathrm{SiO}_{4}$ e $\mathrm{AlO}_{4}$ ligados entre si pelos átomos de oxigênio,

*e-mail: simone_eq@yahoo.com.br formando um arcabouço diversificado, contendo cavidades e canais, normalmente ocupados por moléculas de água e cátions de metais alcalinos e/ou alcalinos terrosos, como íons de compensação. ${ }^{16,17}$ Mais adiante, foi constatada a existência de minerais contendo todos os requisitos básicos para serem classificados como zeólitas, menos aqueles contendo $\mathrm{P}, \mathrm{Be}$, ou outros elementos, que não $\mathrm{Si}$ e $\mathrm{Al}$ nos sítios tetraédricos. ${ }^{17,18}$ Atualmente, a definição de zeólita defendida pelo Subcommittee on Zeolites of the International Mineralogical Association, Commission on New Minerals and Mineral Names, ${ }^{19}$ abrange muito mais do que somente tectossilicatos e considera zeólita todo material cristalino com estrutura caracterizada por um arcabouço de tetraedros $\left(\mathrm{TO}_{4}\right)$ interligados, cada um consistindo de quatro oxigênios envolvendo um cátion "T". Esse arcabouço contém cavidades abertas, na forma de canais e "gaiolas", normalmente ocupadas por moléculas de água e cátions, em geral, trocáveis. ${ }^{17} \mathrm{~A}$ Structure Commission of the International Zeolite Association classifica as zeólitas segundo um código de três letras maiúsculas para cada tipo de estrutura, exemplos: estilbita $=$ STI, mordenita $=$ MOR, faujazita $=$ FAU, sodalita $=$ SOD.$^{20}$

O mineral sodalita, com a composição química $\mathrm{Na}_{8}\left[\mathrm{AlSiO}_{4}\right]_{6} \mathrm{Cl}_{2}$, foi descoberto por Thomson, ${ }^{21}$ e teve sua estrutura descrita primeiramente por Pauling. ${ }^{22}$ Com o desenvolvimento de diferentes métodos de síntese, tem-se chegado a sodalitas com uma vasta variedade na composição. ${ }^{23-27}$ Com base nas interações entre átomos hospedeiros e átomos hóspedes, sodalitas com diferentes características químicas são descritas, as quais podem pertencer à categoria de feldspatoides, zeólitas ou clatratos. ${ }^{23}$ Para os mineralogistas, a sodalita natural com composição típica descrita anteriormente é um feldspatoide, em vez de zeólita, porque não contém água nas cavidades, ocupadas somente por ânions de cloro. ${ }^{28}$ No entanto, sodalitas sintetizadas sobre condições diferentes daquelas encontradas no ambiente natural apresentam outras composições, como é o caso da família hidroxissodalita "HS", também designada sodalita básica "BS" ou sodalita hidratada "ZH". Estas já contêm moléculas de água nas cavidades e canais, o que caracteriza água zeolítica, favorecendo sua classificação no grupo das zeólitas, como se tem feito. Além disso, é importante considerar a topoquímica dos materiais da classe SOD, uma vez que a subunidade sodalita, também conhecida como $\beta$-cavidade, pode se "fundir" de diferentes maneiras para formar estruturas zeolíticas em comum: ${ }^{28,29}$ zeólita A (LTA), zeólitas X/Y (FAU) e EMT. Sendo importante considerar, ainda, a quase inevitável presença de 
hidroxissodalita nos processos de síntese dessas e de outras zeólitas, como também no processo de beneficiamento de alumina (Processo Bayer) ${ }^{30-32}$ Contudo, seria mais adequado classificá-la como clatrato, já que apresenta poros de comunicação com abertura muito pequena, embora a densidade da estrutura seja de 17,2 átomos -T por $1000 \AA^{3}$, valor compatível às das zeólitas..$^{29,33}$

A sodalita sintética pode ser descrita pela fórmula geral $\mathrm{M}_{\mathrm{m}}\left[\mathrm{TO}_{4}\right]$ ${ }_{\mathrm{t}} \mathrm{X} \cdot \mathrm{qH} \mathrm{H}_{2} \mathrm{O}$, onde $\mathrm{M}=\mathrm{Na}^{+}, \mathrm{Ca}^{2+}, \mathrm{K}^{+} \ldots ; \mathrm{X}=\mathrm{OH}^{-}, \mathrm{CO}_{3}{ }^{2-}, \mathrm{Cl}^{-}, \mathrm{SO}_{4}^{2-} \ldots ; 0$ $<\mathrm{q}<2$ e $\mathrm{T}$ átomos que ocupam os sítios tetraédricos ( $\mathrm{Si}, \mathrm{Al}, \mathrm{Ge}$, Ga e B). Sua rede estrutural está baseada na "fusão" de subunidades sodalita, que formam cavidades e canais interconectados, em que as entradas e saídas são controladas por anéis formados a partir de seis membros tetraédricos, com diâmetro cinético de abertura 2,65 Å. A princípio, somente moléculas muito pequenas, tais como hélio (2,6 $)$ ), amônia (2,5 $)$ e água (2,65 $)$, podem acessar e entrar nos canais e cavidades, o que faz da sodalita uma candidata em potencial na separação de moléculas pequenas. ${ }^{23}$ Assim, a separação de água de misturas com álcool ou $\mathrm{H}_{2}$, por exemplo, pode ser possível. Para Khajavi et al. ${ }^{23}$ a separação total de água pode ser conseguida através de membrana de hidroxissodalita sem defeito.

Quando a hidroxissodalita apresenta altos valores de CTC (capacidade de troca catiônica) - normalmente aquela conseguida através de um sistema que converte eficientemente os reagentes em hidroxissodalita como única fase bem cristalizada - pode ser usada no melhoramento de solos e no tratamento de águas residuais, atuando como trocador iônico inorgânico ou um agente adsorvente iônico, capaz de remover cátions como $\mathrm{NH}_{4}{ }^{+}$de águas industriais e de esgotos. ${ }^{24}$

$\mathrm{Na}$ busca por um procedimento de síntese que resulte em sodalita básica como única fase zeolítica de boa cristalinidade, o presente trabalho teve como objetivo, além de apresentar uma finalidade para o rejeito da indústria do caulim, produzir sodalita básica a baixo custo para possíveis aplicações no tratamento de efluentes e na agricultura. Para isso foram desenvolvidos estudos focalizados na síntese e caracterização desse material, visando sempre, além dos benefícios econômicos que poderão ser alcançados com o reaproveitamento do rejeito, o beneficio ambiental que isso trará.

\section{PARTE EXPERIMENTAL}

\section{Fontes de $\mathrm{Si}, \mathrm{Al}$ e Na}

Como fonte de $\mathrm{Si}$ e $\mathrm{Al}$ foi utilizado rejeito caulinítico fornecido por uma indústria de beneficiamento de caulim, localizada no município de Ipixuna, na região Nordeste do Estado do Pará. Como os elementos de interesse fazem parte da estrutura cristalina da caulinita, fez-se necessário um pré-tratamento térmico (calcinação a $700{ }^{\circ} \mathrm{C}$ por $2 \mathrm{~h}$ ) para que toda caulinita se transformasse em metacaulinita, que tem característica amorfa à difração de raios $\mathrm{X}$.

Como fontes de $\mathrm{Na}$ foram usados os álcalis $\mathrm{Na}_{2} \mathrm{CO}_{3}$ e $\mathrm{NaOH}$, ambos da marca Nuclear.

\section{Processo de síntese hidrotermal}

A síntese hidrotermal de sodalita básica, $\mathrm{Na}_{8}\left[\mathrm{AlSiO}_{4}\right]_{6}\left(1 / 2 \mathrm{CO}_{3}, \mathrm{OH}\right)_{2}$. $\mathrm{qH}_{2} 0,0<\mathrm{q}<2$, foi realizada em autoclave de aço inox com revestimento interno de teflon e capacidade máxima de $50 \mathrm{~mL}$. Todos os ensaios foram realizados na temperatura de $150^{\circ} \mathrm{C}$ e pressão autógena, por um período fixo de $24 \mathrm{~h}$.

Na definição dos procedimentos de síntese a serem estudados, levou-se em consideração o preço e as quantidades dos reagentes sódicos envolvidos no processo. Em geral, a base sódica usada nos métodos de síntese de membros da família sodalita é o hidróxido de sódio que, devido a suas propriedades, tem sido o reagente mais apropriado, além de ser de baixo custo. Neste trabalho, buscou-se uma alternativa de reagente sódico que respondesse tão bem quanto aquele e que também fosse barato, no caso, o carbonato de sódio. Assim, $1 \mathrm{~g}$ de rejeito caulinítico calcinado foi, primeiramente, misturado com $33 \mathrm{~mL}$ de solução sódica a diferentes concentrações de $\mathrm{Na}_{2} \mathrm{CO}_{3}$ $(0,4 ; 0,6$ e $1 \mathrm{M})$ e depois a mesma composição dos três ensaios foi acrescentada com 1,5 mL de $\mathrm{NaOH}(5 \mathrm{M})$.

Após as sínteses, as amostras foram filtradas e lavadas com água destilada até $\mathrm{pH} \sim 7 \mathrm{e}$, em seguida, secas a $100^{\circ} \mathrm{C}$ por $8 \mathrm{~h}$. Apresentase na Tabela 1 a identificação dos sólidos sintetizados nas duas séries de meios estudados.

Tabela 1. Identificação dos ensaios

\begin{tabular}{lccc}
\hline Série & Amostras & $\mathrm{NaOH}(\mathrm{mol} / \mathrm{L})$ & $\mathrm{Na}_{2} \mathrm{CO}_{3}(\mathrm{~mol} / \mathrm{L})$ \\
\hline \multirow{3}{*}{$\mathrm{A}$} & $\mathrm{P} 1$ & - & 0,4 \\
& $\mathrm{P} 2$ & - & 0,6 \\
& $\mathrm{P} 3$ & - & 1,0 \\
$\mathrm{H}$ & $\mathrm{P} 4$ & 5 & 0,4 \\
& $\mathrm{P} 5$ & 5 & 0,6 \\
& $\mathrm{P} 6$ & 5 & 1,0 \\
\hline
\end{tabular}

\section{Caracterização dos materiais}

Os materiais sintetizados, bem como o rejeito caulinítico e o rejeito metacaulinizado, foram caracterizados por difração de raios $\mathrm{X}$ (DRX), espectroscopia na região do infravermelho (EIV) e microscopia eletrônica de varredura (MEV).

\section{Difração de raios $X(D R X)$}

As análises foram realizadas em difratômetro modelo X'PERT PRO MPD (PW 3040/60) da PANalytical, com goniômetro PW3050/60 $(\theta / \theta)$, tubos de raios $\mathrm{X}$ cerâmico e anodos de $\mathrm{Cu}$ (K $\alpha 1=1,540598 \AA$ ), modelo PW3373/00 com foco fino longo $(2200 \mathrm{~W}-60 \mathrm{kV})$, filtro $\mathrm{K} \beta$ de níquel e $\mathrm{Co}\left(\mathrm{K} \alpha_{1}=1,789 \AA\right)$, modelo PW3373/00 com foco fino longo ( $1800 \mathrm{~W}-60 \mathrm{kV}$ ), filtro K $\beta$ de ferro. As condições instrumentais utilizadas foram varredura de $5^{\circ}$ a $75^{\circ}$ em $2 \theta$; voltagem de $40 \mathrm{kV}$ e corrente de $35 \mathrm{~mA}$; tamanho do passo: $0,02^{\circ}$ em $2 \theta$ e 20 s o tempo/passo; fenda divergente de $1 / 8^{\circ}$ e antiespalhamento de $1 / 4^{\circ}$; máscara de $10 \mathrm{~mm}$; amostra em movimentação circular com frequência de 1 rotação/s.

\section{Espectroscopia na região do infravermelho (EIV)}

Para a análise, o equipamento utilizado foi um espectrofotômetro Perkin Elmer FTIR 1760X, região espectral de 4000-400 cm-1 com resolução de $4 \mathrm{~cm}^{-1}$ e amostras preparadas em pastilha de $\mathrm{KBr}$.

\section{Microscopia eletrônica de varredura (MEV)}

As micrografias foram obtidas por um MEV modelo LEO-1430, sendo as condições de análises para as imagens de elétrons secundários: corrente do feixe de elétrons $=90 \mu \mathrm{A}$, voltagem de aceleração constante $=20 \mathrm{kv}$, distância de trabalho $=10 \mathrm{~mm}$.

Análises químicas (elementos maiores e traços) foram realizadas através de 4 procedimentos/metodologias distintas. Os elementos maiores e alguns traços foram analisados através de espectrometria de emissão por ICP, após abertura por fusão com metaborato/tetraborato de lítio e digestão em ácido nítrico diluído. Porém, para alguns elementos traços, como os ETR e outros que apresentam refratariedade, utilizou-se ICPMS, com o mesmo procedimento de decomposição da amostra descrito anteriormente. Para os elementos metálicos e preciosos, a amostra foi diluída em água régia, antes de ser analisada por ICP-MS. A perda ao fogo foi determinada por diferença de massas após calcinação da amostra a $1000{ }^{\circ} \mathrm{C}$. Adicionalmente, algumas análises foram realizadas por 
fluorescência de raios X (espectrômetro Axios-Minerals, da Panalytical) em pastilha fundida ( $1 \mathrm{~g}$ de amostra para $8 \mathrm{~g}$ de metaborato de lítio), utilizando o programa IQ+, também da Panalytical.

\section{RESULTADOS E DISCUSSÃO}

\section{Rejeito caulinítico e rejeito caulinítico calcinado}

O resultado da análise química do rejeito caulinítico, apresentado na Tabela 2, mostra que $\mathrm{SiO}_{2}$ e $\mathrm{Al}_{2} \mathrm{O}_{3}$ são os componentes principais no material analisado, correspondendo a $82,82 \%$. Os outros componentes, desconsiderando-se a perda ao fogo- $15,40 \%$, somam menos de $2 \%$. Os teores obtidos de sílica, alumina e da perda ao fogo, estão próximos dos valores teóricos da caulinita.

Tabela 2. Composição química do rejeito caulinítico

\begin{tabular}{lcc}
\hline Constituintes (\%) & Rejeito Caulinítico & Caulinita Teórica \\
\hline $\mathrm{SiO}_{2}$ & 45,30 & 46,54 \\
$\mathrm{Al}_{2} \mathrm{O}_{3}$ & 37,52 & 39,50 \\
$\mathrm{Fe}_{2} \mathrm{O}_{3}$ & 0,59 & - \\
$\mathrm{TiO}_{2}$ & 0,91 & - \\
$\mathrm{CaO}$ & $<0,01$ & - \\
$\mathrm{MgO}$ & 0,02 & - \\
$\mathrm{Na}_{2} \mathrm{O}$ & 0,04 & - \\
$\mathrm{K}_{2} \mathrm{O}$ & 0,10 & - \\
P.F & 15,40 & 13,96 \\
\hline
\end{tabular}

P.F: perda ao fogo

A Figura 1 apresenta o difratograma do rejeito caulinítico (RC). Verifica-se que o mesmo é composto essencialmente pelo argilomineral caulinita, como pode ser comprovado pelos picos principais (7,15 e 3,57 ̊). Verifica-se ainda, a presença de muscovita $(9,94 \AA)$, anatásio $(3,52 \AA)$ e quartzo $(3,34 \AA)$, em teores bem baixos.

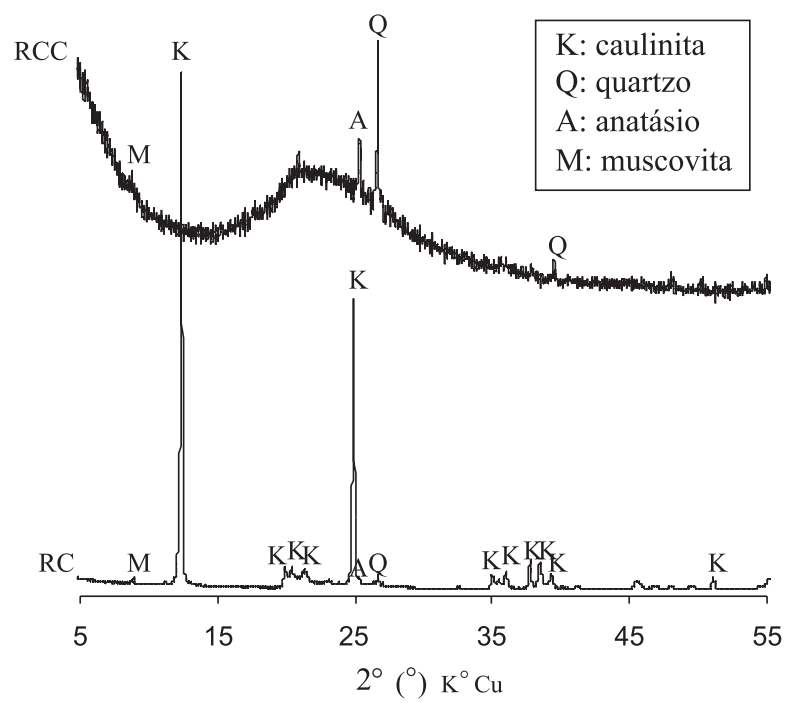

Figura 1. Difratogramas de raios $X$ do rejeito caulinítico $(R C)$ e rejeito caulinítico calcinado $(R C C)$

Ainda na Figura 1, tem-se o difratograma do rejeito caulinítico calcinado (RCC) a $700{ }^{\circ} \mathrm{C}$ por $2 \mathrm{~h}$. Como era de se esperar, houve o total rompimento da estrutura cristalina da caulinita, devido sua desidroxilacão. ${ }^{11,12}$ Ainda são detectados os picos de muscovita, anatásio e quartzo, já que para destruir a estrutura destes minerais seriam necessárias temperaturas muito mais elevadas do que $700^{\circ} \mathrm{C}$.
Analisando os espectros de absorção no infravermelho (Figura 2), observa-se em RC a presença marcante de bandas características da caulinita e, em RCC, as mudanças após a calcinação, que se apresentam em total acordo com as relatadas na literatura: ${ }^{34,35}$ a 3695 e $3651 \mathrm{~cm}^{-1}$, correspondentes à presença da hidroxila, devido à vibração perpendicular e à vibração paralela ao plano $a b$, respectivamente. Entre $1100-1000 \mathrm{~cm}^{-1}$ as bandas de vibração da ligação Si-O; a 910 $\mathrm{cm}^{-1}$ banda de deformação Al-OH; em 800,752 e $530 \mathrm{~cm}^{-1}$ as bandas de vibração da ligação Si-O-Al e, a 693, 465 e $425 \mathrm{~cm}^{-1}$ as bandas características da ligação Si-O. A presença de uma banda larga em $3422 \mathrm{~cm}^{-1}$ e outra em $1620 \mathrm{~cm}^{-1}$ corresponde à ligação $\mathrm{O}-\mathrm{H}$ da água livre, presente nos dois espectros. O desaparecimento da banda 910 $\mathrm{cm}^{-1}$ no espectro RCC indica perda das unidades Al-OH. As mudanças nas bandas de estiramento $\mathrm{Si}-\mathrm{O}$ e desaparecimento da banda Al-O-Si a $792 \mathrm{~cm}^{-1}$ correspondem às distorções das camadas tetraédricas e octaédricas. Assim, os espectros RC e RCC indicam a transformação da caulinita em metacaulinita sob condições de $700^{\circ} \mathrm{C}$ por um período de $2 \mathrm{~h}$, o que satisfaz o pretendido, que era destruir a estrutura da caulinita para deixar o Si e Al mais acessíveis na síntese da sodalita.

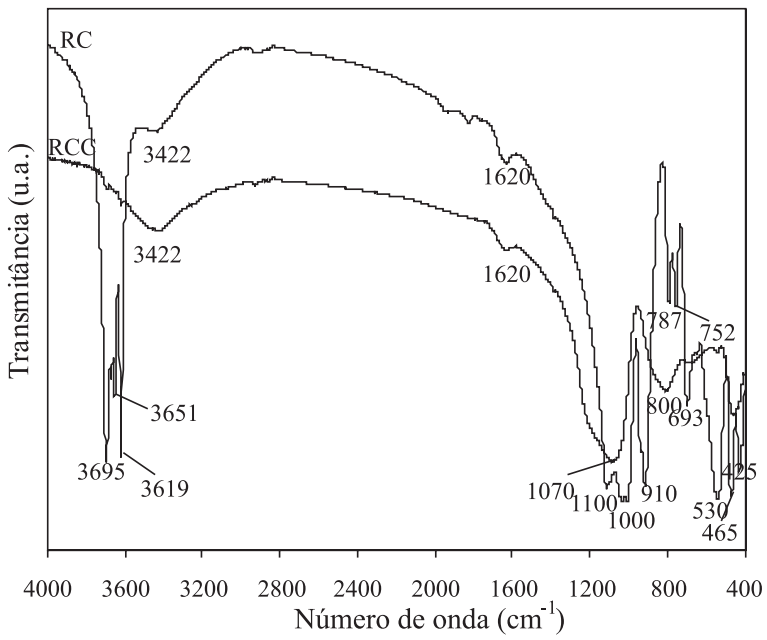

Figura 2. Espectros vibracionais do RC e RCC

\section{Produtos de síntese}

A composição química dos sólidos produzidos (Tabela 3) mostra que a razão $\mathrm{Si} / \mathrm{Al}$ obtida, próxima de 1 , condiz com a da sodalita básica, que pertence à classe das zeólitas com baixo teor de silício que, por sua vez, tem a mesma relação $\mathrm{Si} / \mathrm{Al}$ da caulinita e metacaulinita. Observa-se ainda que os produtos P3, P4, P5 e P6 apresentaram teores de sódio bem próximos entre si e maiores do que P1 e P2.

Tabela 3. Análise química dos produtos de síntese por FRX (\% massa)

\begin{tabular}{lcccccccc}
\hline Amostra & $\mathrm{SiO}_{2}$ & $\mathrm{Al}_{2} \mathrm{O}_{3}$ & $\mathrm{Na}_{2} \mathrm{O}$ & $\mathrm{Fe}_{2} \mathrm{O}_{3}$ & $\mathrm{TiO}_{2}$ & $\mathrm{~K}_{2} \mathrm{O}$ & $\mathrm{CaO}$ & P.F \\
\hline P1 & 51,13 & 38,70 & 1,98 & 0,68 & 1,08 & 0,07 & 0,04 & 6,24 \\
P2 & 42,88 & 32,20 & 12,73 & 0,58 & 0,84 & 0,06 & 0,03 & 10,65 \\
P3 & 35,49 & 27,84 & 20,52 & 0,44 & 0,74 & 0,02 & 0,06 & 14,84 \\
P4 & 37,25 & 27,52 & 19,11 & 0,51 & 0,71 & 0,06 & - & 14,81 \\
P5 & 36,52 & 26,71 & 20,35 & 0,49 & 0,65 & 0,04 & 0,01 & 15,2 \\
P6 & 36,31 & 27,39 & 20,74 & 0,41 & 0,69 & 0,03 & 0,05 & 14,04 \\
\hline
\end{tabular}

A Figura 3 ilustra os difratogramas dos sólidos obtidos a partir de soluções de $\mathrm{Na}_{2} \mathrm{CO}_{3}$. Observa-se que em P1 houve uma sutil formação de sodalita, em P2 uma formação um pouco maior e só em P3 se teve a maior conversão de metacaulinita em sodalita básica de boa cristalinidade, dentre as demais da série A. A Figura 4 mostra 
os difratogramas dos sólidos obtidos a partir de soluções contendo $\mathrm{Na}_{2} \mathrm{CO}_{3}$ e $\mathrm{NaOH}$ (série B). Em P4 e P5 houve uma maior formação de sodalita com o acréscimo de $\mathrm{NaOH}$, em relação aos seus correspondentes da série A sem ele, $\mathrm{P} 1$ e P2, respectivamente; o que mostra a forte influência de $\mathrm{NaOH}$ na cinética de reação.

Comparando todos da série B (Figura 4) com P3 da série A (Figura 3) não se observam diferenças significativas, quanto à difratometria de raios X, mostrando que para essas condições, a conversão de metacaulinita em sodalita básica foi alta e de boa cristalinidade. Nas duas séries estudadas, sodalita básica foi a única fase zeolítica formada, resultado bastante satisfatório, uma vez que misturas zeolíticas são muito comuns nos estudos de síntese.

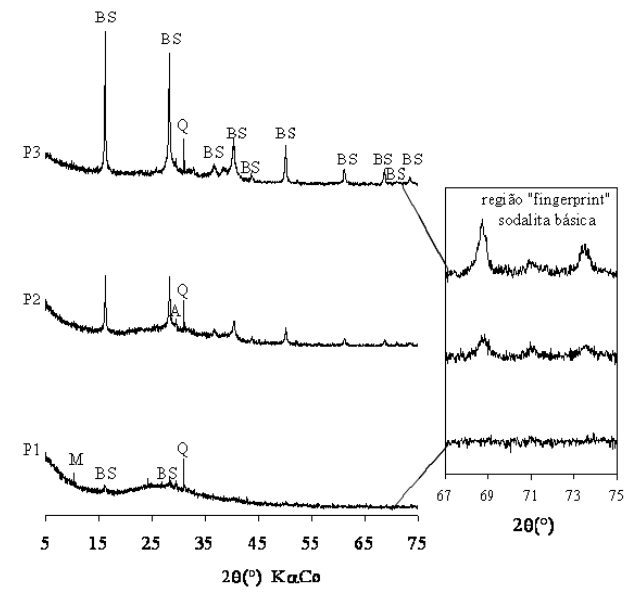

Figura 3. Difratogramas de raios $X$ dos produtos da série A (P1, P2 e P3); BS: sodalita básica, Q: quartzo, A: anatásio, M: muscovita

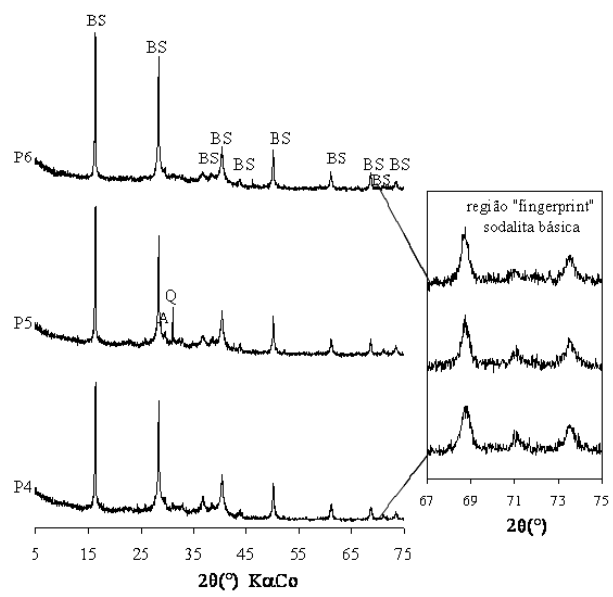

Figura 4. Difratogramas de raios $X$ dos produtos da série B (P4, P5 e P6); BS: sodalita básica, Q: quartzo, A: anatásio

A espectroscopia no IV foi aplicada para uma melhor caracterização do material obtido, incluindo detalhes das diferentes misturas metacaulinita/sodalita, com base nas bandas de absorção dessas duas fases, listadas na Tabela 4.

Os espectros vibracionais (Figuras 5 e 6) tornaram possível a identificação das espécies hospedadas dentro das cavidades sodalita $\left(\mathrm{OH}: 3640 \mathrm{~cm}^{-1} ; \mathrm{H}_{2} \mathrm{O}: 3600-3000 \mathrm{~cm}^{-1}, 1650 \mathrm{~cm}^{-1} ; \mathrm{CO}_{3}^{2-*}: 1450 \mathrm{~cm}^{-1}\right)$. Foi possível ainda, acompanhar a transformação de metacaulinita em sodalita, pelo desaparecimento da banda $803 \mathrm{~cm}^{-1}$, característica da metacaulinita, e surgimento das bandas 660 e $705 \mathrm{~cm}^{-1}$, características da sodalita básica. Tais mudanças são pouco perceptíveis em P1, devido a pouca transformação ocorrida, como também mostram o
Tabela 4. Bandas de absorção no IV características da sodalita básica e metacaulinita

\begin{tabular}{lc}
\hline sodalita básica ${ }^{7}\left(\mathrm{~cm}^{-1}\right)$ & metacaulinita $^{31}\left(\mathrm{~cm}^{-1}\right)$ \\
\hline 430 & 453 \\
465 & 476 \\
660 & 803 \\
705 & 1063 \\
731 & \\
$1450\left(\mathrm{CO}_{3}^{2-}\right)$ & \\
1650 & \\
$3000-3600$ & \\
3640 & \\
\hline
\end{tabular}

difratograma e a composição química. As bandas próximas de 3600 e $1000 \mathrm{~cm}^{-1}$ estão presentes em todos os espectros apresentados e exibem poucas diferenças, já que são vibrações de grupos funcionais comuns nos dois materiais, $\mathrm{O}-\mathrm{H}$ e $\mathrm{Si}-\mathrm{O}$, respectivamente.

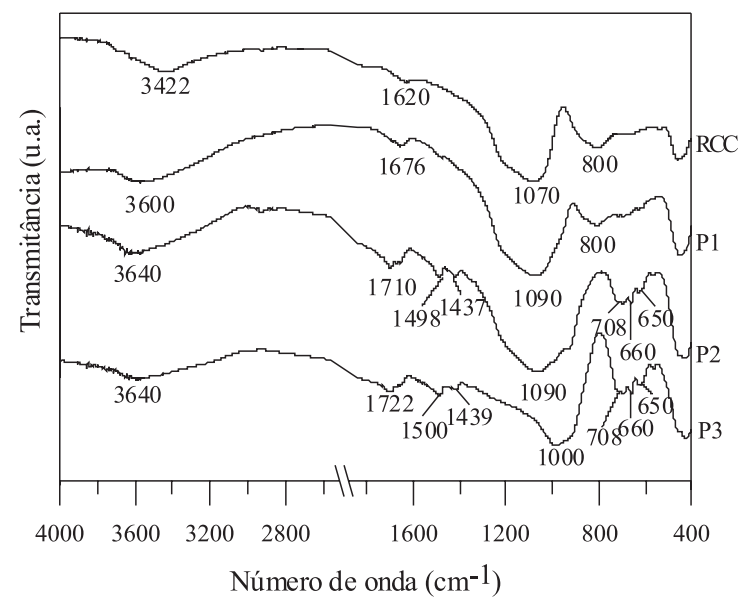

Figura 5. Espectros vibracionais do RCC e dos produtos da série A ( $P 1$, P2 e P3)

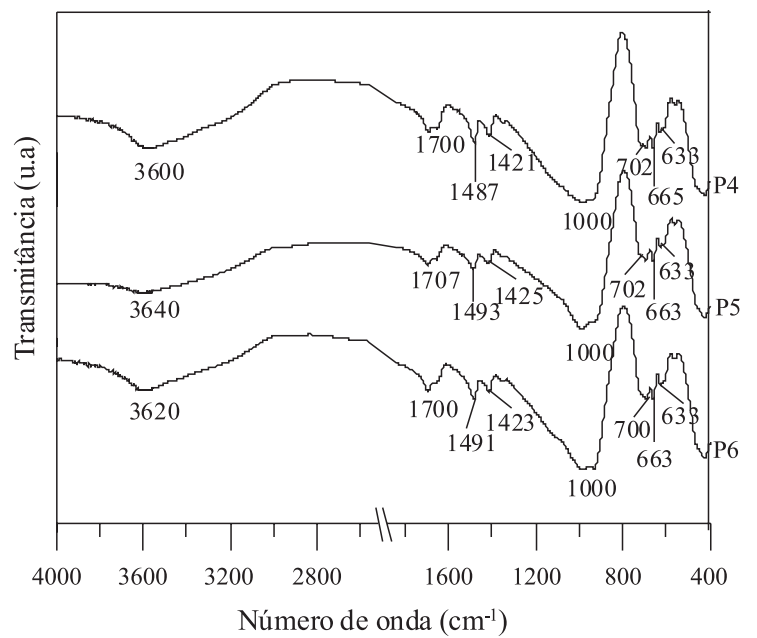

Figura 6. Espectros vibracionais da série B (P4, P5 e P6)

As Figuras $1 \mathrm{~S}$ e $2 \mathrm{~S}$ (material suplementar) correspondem às micrografias do rejeito caulinítico e rejeito caulinítico calcinado, respectivamente. Por ser constituído predominantemente de caulinita, a morfologia do rejeito, antes da calcinação, corresponde exatamente à relatada na literatura para esse argilomineral: ${ }^{4,11}$ morfologia dos cristais pseudo-hexagonais e empilhamento tipo booklets. Após a calcinação, 
a forma pseudo-hexagonal é mantida, mas o empilhamento é alterado pela diminuição de folhas empacotadas ao longo do eixo $c$. Pelas micrografias dos sólidos obtidos (Figuras de $3 \mathrm{~S}$ a $8 \mathrm{~S}$, material suplementar) é possível identificar o progresso da transformação metacaulinitasodalita, mediante análise das variações morfológicas resultantes. A sodalita básica é facilmente identificada pelas formas arredondadas características dos policristais, tipo novelos de lã, que crescem e se aglomeram repetidas vezes. A Figura $3 \mathrm{~S}$ apresenta a micrografia do sólido de menor conversão e as Figuras de $5 \mathrm{~S}$ a $8 \mathrm{~S}$, os de maior.

Finalmente, com o emprego das técnicas de FRX, DRX, EIV e MEV foi possível observar que maiores quantidades de reagentes sódicos, acima das usadas nos ensaios P3 (série A) e P4 (série B), não alteraram significamente a taxa de conversão, como também a cristalinidade da sodalita básica, mostrando que o equilíbrio químico para as condições de síntese empregadas possivelmente foi alcançado em P3 e P4.

A partir da literatura ${ }^{24}$ e dos resultados alcançados para $\mathrm{P} 3$ e P4 é possível prever a utilização da sodalita básica sintetizada a baixo custo em tratamentos de efluentes e na agricultura.

\section{CONCLUSÕES}

De acordo com os resultados apresentados, pode-se concluir que é possível produzir sodalita básica de boa cristalinidade a partir de rejeito caulinítico termicamente ativado, sendo os procedimentos $\mathrm{P} 3$ e P4 os mais adequados, diante dos objetivos traçados, nas condições de síntese empregadas.

Pode-se afirmar, ainda, que o rejeito caulinítico produzido por uma indústria de caulim da Amazônia poderá ser perfeitamente reaproveitado na produção de sodalita básica, que poderá ser utilizada em tratamentos de controle ambiental como, por exemplo, no tratamento de águas residuais de indústrias e esgotos. Isso significa que o rejeito poderá sair da condição de poluente para a condição de solução de problemas ambientais.

Estudos futuros de CTC e aplicações em tratamentos de efluentes e/ou melhoramento de solos, poderão confirmar a importância da sodalita sintetizada.

\section{MATERIAL SUPLEMENTAR}

As Figuras $1 \mathrm{~S}$ e $2 \mathrm{~S}$ referentes às micrografias do rejeito caulinítico e rejeto caulinítico calcinado, assim como as Figuras de $3 \mathrm{~S}$ a $8 \mathrm{~S}$ referentes às micrografias dos produtos de síntese estão disponíveis em http://quimicanova.sbq.org.br na forma de arquivo PDF, com acesso livre.

\section{AGRADECIMENTOS}

Ao $\mathrm{CNPq}$ pelo auxílio financeiro (Edital Universal, Projeto 474.058/2006-9), bolsa de mestrado da primeira autora (Processo: 131.752/2008-1) e pela bolsa de produtividade em pesquisa do último autor (Processo: 304.566/2007-1); e ao Prof. Dr. C. Lamarão, do Laboratório de Microscopia Eletrônica de Varredura-IG (UFPA), pelas análises de MEV.

\section{REFERÊNCIAS}

1. Barata, M. S.; Angélica, R. S.; Pollmann, H.; Costa, M. L.; Eur. J. Mineral. 2005, 17, 10
2. Barata, M. S.; Molin, D. C. C. D.; Antac 2002, 2, 69

3. http://www.dnpm.org.br, acessada em Agosto 2009.

4. Maia, A. A. B.; Saldanha, E.; Angélica, R. S.; Souza, C. A. G.; Neves, R. F.; Cerâmica 2007, 53, 319.

5. Maia, A. A. B.; Angélica, R. S.; Neves, R. F.; Cerâmica 2008, 54, 345.

6. Breck, D. W.; Zeolitic Molecular Sieves, Wiley: New York, 1974.

7. Mignoni, M. L.; Petkowicz, D. I.; Machado, N. R. C. F.; Pergher, S. R. C.; Appl. Clay Sci. 2008, 41, 99.

8. Buhl, J. C.; Hoffman, W.; Buckermann, W. A.; Muller-Warmuth, W.; Solid State Nucl. Magn. Reson. 1997, 9, 121.

9. Alkan, M.; Hopa, Ç.;Yilmaz, Z.; Güler, H.; Microporous Mesoporous Mater. 2005, 86, 176

10. Murray, H.; Bundy, W.; Harvey, C.; Kaolin Genesis and Utilization, The Clay Minerals Society, 1993.

11. Santos, P. S.; Ciência e Tecnologia de Argilas, $2^{\mathrm{a}}$ ed., Edgar Blucher: São Paulo, 1989, vol.1.

12. Gomes, C. F.; Argilas - o que são e para que servem, Fundação Calouste Gulbenkian: Lisboa, 1988.

13. Gardolinski, J. E.; Martins, H. P. F.; Wypych, F.; Quim. Nova 2003, 26, 30.

14. Neves, C. F. C.; Schvartzman, M. M. A. M.; Quim. Nova 2005, 28, 622.

15. Kazemimoghadam, M.; Mohammadi, T.; Desalination 2007, 206, 547.

16. Luz, A. B.; Série tecnológica Mineral, Cetem: Rio de Janeiro, 1995.

17. Resende, N. G. A. M.; Monte, M. B. M.; Rochas e Minerais industriais, Cetem: Rio de Janeiro 2005, cap. 33

18. Luna, F. J.; Schuchardt, U.; Quim. Nova 2001, 24, 885.

19. Coombs, D. S.; Alberti, A.; Armbruster, T.; Artioli, G.; Colella, C.; Galli, E.; Grice, J. D.; Liebau, F.; Mandarino, J. A.; Minato, H.; Nickel, E. H.; Passaglia, E.; Peacor, D. R.; Quarturi, S.; Rinaldi, R.; Ross, M.; Sheppard, R. A.; Tillmanns, E.; Vezzalini, G.; Can. Mineral. 1997, 35, 1571.

20. Baerlocher, C.; Meier, W. M.; Olson, D. H.; Atlas of zeolite framework, $5^{\text {th }}$ ed., Elsevier, 2001.

21. Thomson, T.; Journal of Natural Philosophy, Chemistry and the Arts 1811, 29, 285.

22. Pauling, L.; Z. Kristallogr. 1930, 74, 213.

23. Khajavi, S.; Kapteijn, F.; Janse, J. C.; J. Membr. Sci. 2007, 63, 299.

24. Henmi, T.; Japanese Society of Soil Science and Plant Nutrition 1987, $33,517$.

25. Depmeier, W.; Phys. Chem. Miner. 1988, 15, 419.

26. Bibby, D. M.; Dale, M. P.; Nature 1985, 317, 157.

27. Ocanto, F.; Linares, C.; Urbina, C.; Alvarez, R.; Acta Microscópica 2005, 14,15 .

28. Smith, J. V.; Microporous and other Framework Materials with Zeolitetype structures, Springer: New York, 2000, vol. 14.

29. Cejka, J.; Avelino, C., Herman, V. B.; Ferdi, S.; Introduction to zeolite science and Practice, Elsevier, 2007.

30. Armstrong, J. A.; Dann, S. E.; Microporous Mesoporous Mater. 2000 , $41,89$.

31. Barnes, M. C.; Addai-Mensah, J.; Gerson, A. R.; Microporous Mesoporous Mater. 1999, 31, 287.

32. Smith, P.; Wingate, C.; De Silva, L.; Proceeding of the 8th International Alumina Quality Workshop, WA, Australia, 2008.

33. Braga, A. A. C.; Morgon, N. H.; Quim. Nova 2007, 30, 178.

34. Carneiro, B. S.; Angélica, R. S.; Scheller, T.; De Castro, E. A. S.; Neves, R. F.; Cerâmica 2003, 312, 237.

35. Akolekar, D.; Chaffee, A.; Howe, R. F.; Zeolites 1997, 19, 359. 


\section{SÍNTESE HIDROTERMAL DE SODALITA BÁSICA A PARTIR DE UM REJEITO DE CAULIM TERMICAMENTE} ATIVADO

Simone Patrícia Aranha da Paz*, Rômulo Simões Angélica e Roberto de Freitas Neves

Instituto de Geociências, Universidade Federal do Pará, Rua Augusto Corrêa, s/n, 66075-110 Belém - PA, Brasil

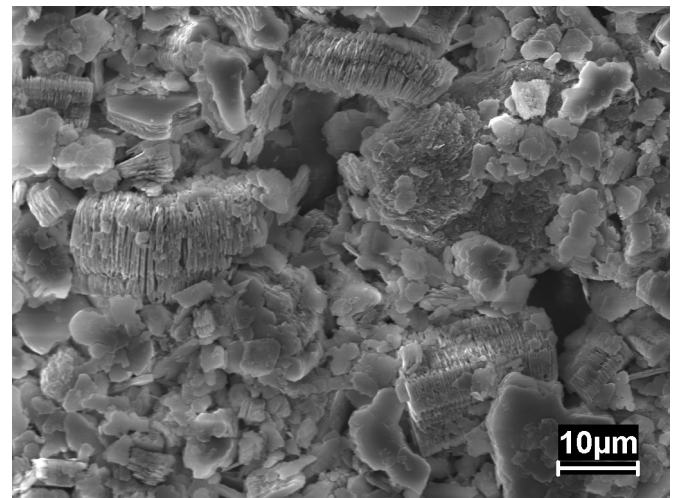

Figura 1S. Micrografia do rejeito caulinítico

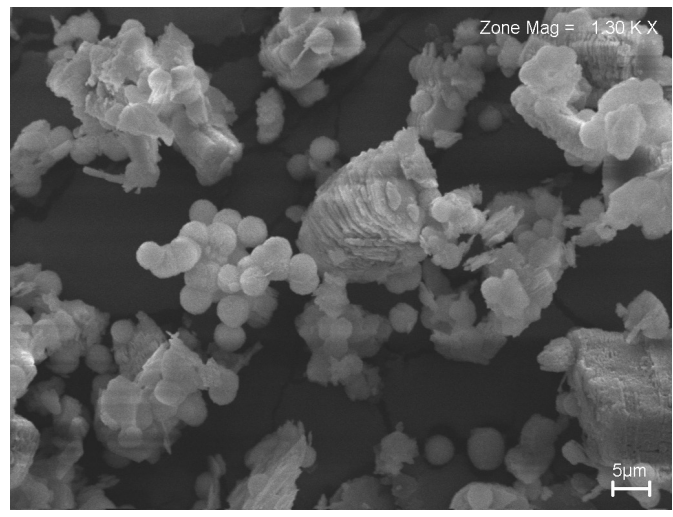

Figura 3S. Micrografia do produto de síntese P1

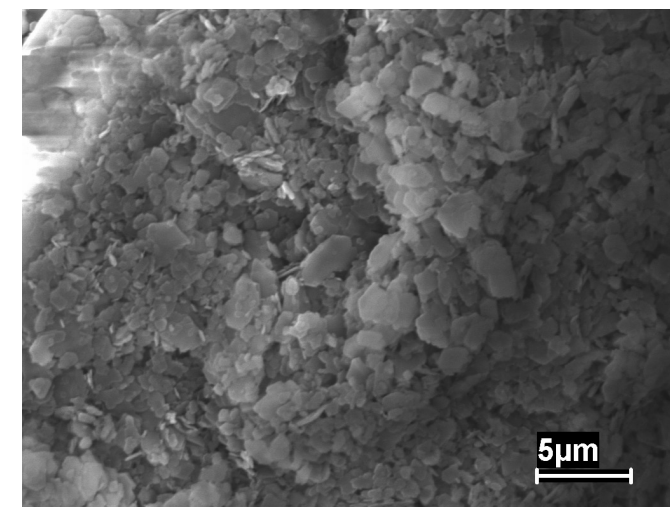

Figura 2S. Micrografia do rejeito caulinítico calcinado

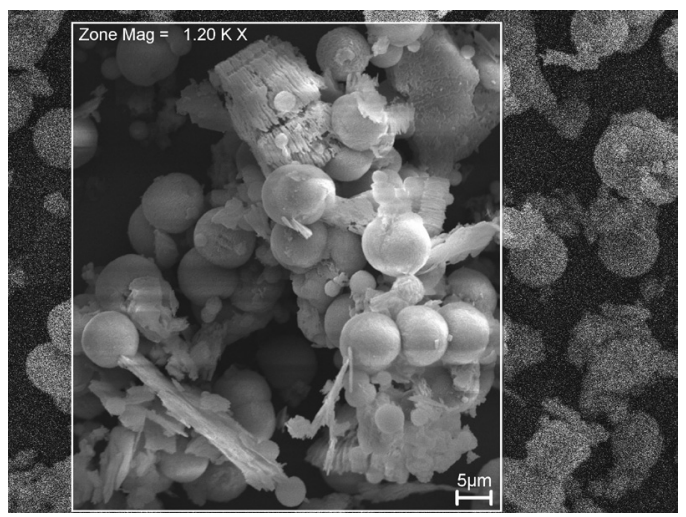

Figura 4S. Micrografia do produto de síntese P2 


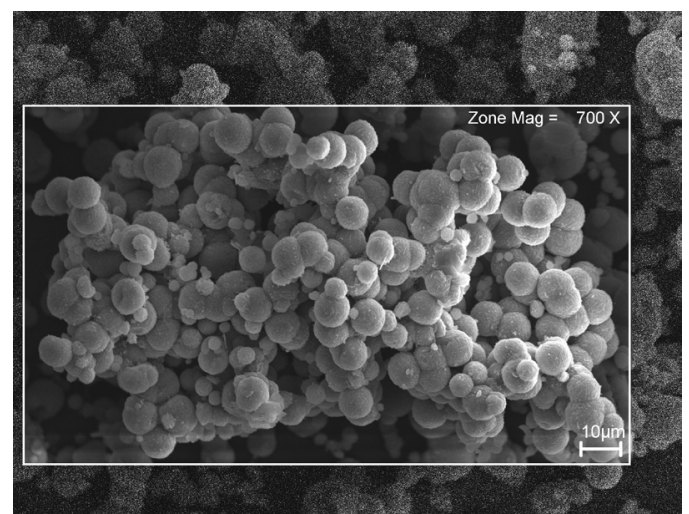

Figura 5S. Micrografia do produto de síntese P3

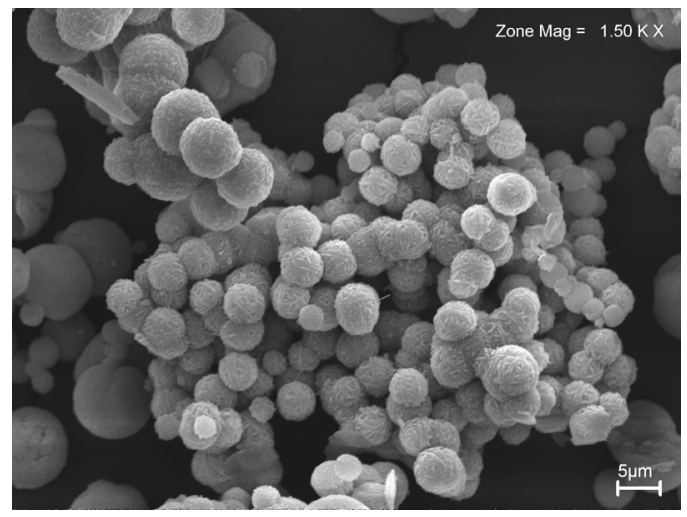

Figura 7S. Micrografia do produto de síntese P5

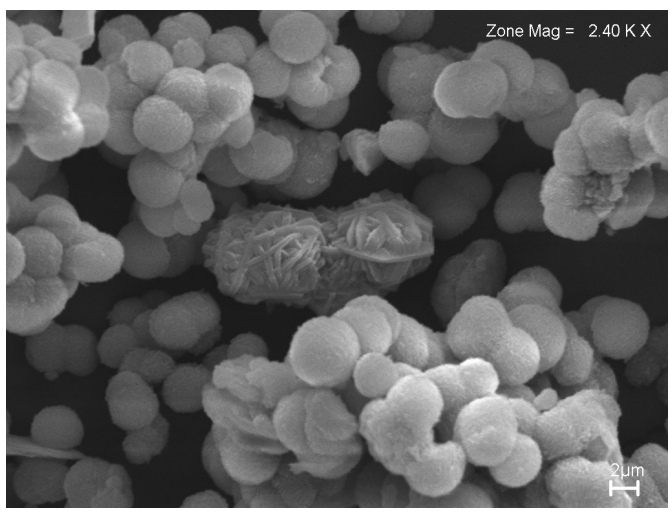

Figura 6S. Micrografia do produto de síntese P4

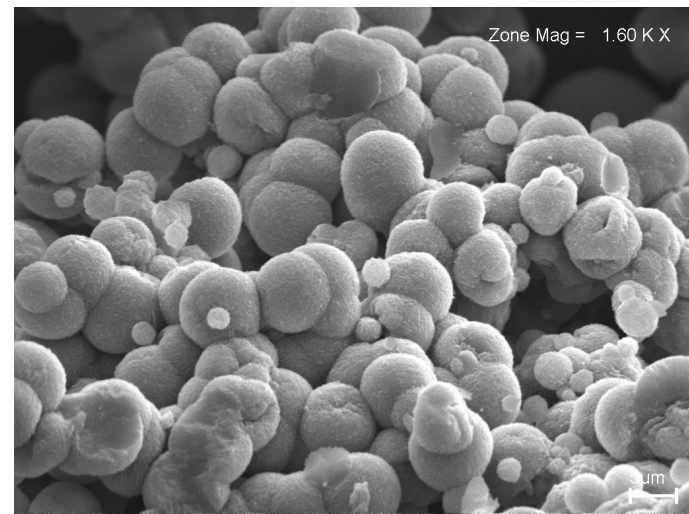

Figura 8S. Micrografia do produto de síntese P6 